\title{
Groundwater Vulnerability Assessment in Shallow Aquifer in Linfen Basin, Shanxi Province, China Using DRASTIC Model
}

\author{
Mamadou SAMAKE(Corresponding author), Zhonghua Tang, Win HLAING, Innocent NDOH MBUE, \\ Kanyamanda Kasereka \& Waheed O. Balogun \\ Key Laboratory of Biogeology and Environmental Geology of Ministry of Education \\ School of Environmental Sciences, China University of Geosciences (CUG) \\ Wuhan, Hubei 430074, China \\ E-mail: sitsam2003@yahoo.fr
}

\begin{abstract}
Groundwater pollution is one of the most serious environmental problems in the world. Human activities, e.g. industrial, agricultural and household represent a real threat for groundwater quality. In areas where Groundwater constitutes the main drinking water resources, its vulnerability assessment, to delineate areas that are more susceptible to contamination has become an important element for water resource management and land use planning. Hence, maps of groundwater vulnerability to pollution are becoming more in demand because this essential resource for life represents the main source of drinking water in many parts of the world and particularly in northern China where there is insufficient surface water.

This study used the ArcGIS 9.2 software and geographical information system (GIS) techniques to apply an EPA model for determining intrinsic vulnerability of groundwater to pollution in Linfen Basin, Shanxi Province, China. The model is called DRASTIC, representing hydrogeological parameters such as Depth to Aquifer, Net Recharge, Aquifer Media, Soil Media, Topography, Impact of vadose Zones, and Hydraulic Conductivity. The DRASTIC model uses environmental parameters to characterize the hydrogeological setting of any area and to evaluate the aquifer vulnerability. The DRASTIC scores obtained from the model vary from 59 to 147, where the higher value implies the relative greater vulnerability. These values were reclassified into three classes: very low, low and moderate vulnerable zones. The moderate vulnerability zones of Linfen Basin are located in the north and southeastern part of the basin. The moderate vulnerable zones cover around 16.38\% of the study area. Huozhou City in the north, Yicheng County, Qu Wo County in the south east are concerned by moderate vulnerability zones.

The very low vulnerable zones are well distributed and are mainly located in the middle and south parts of the basin. Some very low vulnerable zones can also be seen in the north east and extreme east parts. Very low vulnerable zones cover about $40.13 \%$ of the study area. The remaining parts of the Linfen basin are under low vulnerable zones (43.49\%) which are located in the west and Middle West parts of the region.
\end{abstract}

The results of this study can be used to determine where communities should undertake aggressive protection of the groundwater. Regional development planners will benefit from knowledge of local sensitive aquifers.

Keywords: DRASTIC model, Linfen Basin, Groundwater vulnerability, Intrinsic vulnerability

\section{Introduction}

The Earth is a planet with much water but its distribution is uneven. Some parts of the earth are well furnished whereas others are not. Water is known to be a precondition for human, animal and plant life.

Because of that water is the most sought resource for human use. It may be find in surface and the sub-surface of the earth. Surface water knows a great degree of pollution and sometime is unavailable for water supply. Problems with surface water quality have increased recently, primarily due to contamination associated with land use activities, including agricultural activities, leaking municipal sewage treatment facilities, poor septic management; uncontrolled cattle access to water bodies, effluents from industries and runoff from urban areas (Timmer et al. 2005). Thus groundwater becomes the main drinking water resource in many parts of the world.

Groundwater is water that is present below the surface of the earth in underground stream and aquifer. It is one of the most important natural resources in any nation serving as a major source of water to communities, industries and agriculture purposes (Venkataramanan Balasubramanian, 2000). Groundwater has been considered as an important source of water supply due to its relatively low susceptibility to pollution in comparison with surface water and its large storage capacity (USEPA, 1985). Therefore it has to be protected from the increasing threat of subsurface contamination. 
Most parts of northern China do not have sufficient surface water and the dependable water resource is largely groundwater, which has an enormous potential in the country. Official figures show that 884 billion $\mathrm{m}^{3}$ of natural groundwater are replenished each year, with 353 billion $\mathrm{m}^{3}$ available for use. In China, groundwater occupies $31 \%$ of the total water resources, supplies $70 \%$ of drinking water and $40 \%$ of irrigation water (CGS, 2006).

Consequently, groundwater has become an important source of water and has played an important role in developing industry, agriculture, and municipal construction. Groundwater has greatly benefited the development of agriculture by combating drought, ensuring stable agricultural yields, and raising output value. Then sustainable development requires the management and preservation of water resources indispensable for all human activities (Said Ettazarini, 2006)

In Shanxi Province where Linfen Basin is located, water resources represent 15.24 billion $\mathrm{m}^{3}$. The province is deficient in surface water, but the available resources are evenly distributed. Hence, the importance of the vital water resources which is groundwater in Shanxi Province in one hand and to Linfen city in the other hand.

Groundwater is distribution in China is uneven. $67.7 \%$ of groundwater resources are located in the south while $32.3 \%$ are in the north arid areas. China's groundwater management is about 20 years behind the world's most advanced levels, (CGS, 2006).

The major culprit of the worsening groundwater pollution is industrial wastes. Some plants discharge waste without proper treatment due to the poor enforcement of environmental protection laws. An increase in human activities has exacerbated the situation e.g. gas stations have boomed in recent years, causing serious pollution to nearby soil and groundwater.

Nowadays, many important aquifers are exposed to the impact of disordered exploitation and inadequate land use. Contamination resulting from industry, urbanization and agriculture poses a threat to water quality (Vu Thi Minh Nguyet, 2006). Groundwater quality at Linfen Basin is deteriorating. Severe salinization, high total dissolve solids (TDS), and other chemicals which in excess can threaten human health have been found in the groundwater. Pollution impairs the use of water and can be a hazard to public health through toxicity or the spread of disease.

In the past 50 years, groundwater contamination has become one of the serious environmental problems in the world because once polluted the remediation of aquifers may be very difficult and even impossible (Kavanaugh 1996; Mcmahon et al. 1999; Aronovsky 2000).To prevent Groundwater contamination, studies must be carried out to assess and delineate groundwater vulnerable zones to probable contamination. Aquifer vulnerability applies the concept that strata containing water can be influenced by impacts occurring above, below, or laterally adjacent to them. Researchers have also recognized that overlying strata can provide the groundwater source some degree of protection from potential contamination occurring at the ground surface (Foster 1998; Frederic et al. 2004).

The main objective of this paper is an attempt to assess groundwater vulnerability to pollution in shallow aquifer in Linfen basin using DRASTIC method as described by Aller et al. (1987). DRASTIC methodology was developed in the United States under cooperative agreement between the National Water Well Association (NWWA) and the US environmental protection agency (EPA) for pollution potential projection (Rundquist et al. 1991). This model is taking into consideration the most important hydrogeologic factors that influence the pollution potential of groundwater: depth to aquifer, net recharge, aquifer media, soil media, topography, impact of vadose zones, and hydraulic conductivity. (Aller et al.1987).

\section{Materials and Methods}

\subsection{Study area}

The Linfen basin with a surface area of nearly $5,200 \mathrm{~km}^{2}$ and an average width of $30 \mathrm{~km}$ is located in the southwestern part of Shanxi Province on the middle reaches of the Yellow River. The Province has five other large basins (Datong, Xinzhou, Taiyuan, Yuncheng and Changzhi) and small basins scattered around the province, including Yangquan, Shouyang, Xiangyuan, Licheng and Jincheng. Geographically the area extends from latitude $35^{\circ} 23^{\prime}$ to $36^{\circ} 37^{\prime}$ north, and from Eastern longitude $110^{\circ} 22^{\prime}$ east to $112^{\circ} 34^{\prime}$. Huozhou City lies in the northernmost of the Linfen basin and Wanrong high-profile plateau in the southernmost. The east boundary is Taiyue and Zhongtiao Mountain from north to south and the west boundary is Lvliang Mountain and the Yellow river. The distribution of the basin is in the north-northeast direction. The terrain of the basin in the northeast is slightly tilted to that in the southwest. The main cities and counties in the basin area are: Heijin, Jishan, Houma, QuWo, Hongtong, Xiangfen, Huozhou, and Xinjiang (fig.1 and fig.2). 
Linfen Development Zone lies in the southwest of Shanxi, 300 kilometers away from the capital city, Taiyuan. The ground elevation varies from $420 \mathrm{~m}-457 \mathrm{~m}$ high in the basin. The development zone is located in the north Linfen within the $53 \mathrm{~km} 2$ of city planned area.

The Linfen Basin lies in the half arid and half moist monsoon climate area with the temperate continental climate. Four seasons exists in the area: the hot period is accompanied with rain season. It is hot in summer and cold in winter; the period of sunlight is 2417 hours - 2741 hours in the year, the average temperature of the whole year lies between 8.6 degrees to 12.6 degrees; the annual frost-free period is between 193 days to 227 days and the annual precipitation is $500 \mathrm{~mm}$ (Linfen Economic \& Technological Development Zone).

The rapid growth in Linfen population combined with domestic, agricultural and industrial quest of water resource in area known as vulnerable in geological and environmental point of view make necessary an appraisal of the groundwater resources situation.

As quoted above, the methodology used for groundwater vulnerability assessment to pollution in Linfen basin is DRASTIC method. It's the commonly used model for assessing groundwater vulnerability. It has been used in United States (Hearne et al., 1992; Atkinson et al., 1994; Kalinski et al., 1994). Merchant J.W (1994) applied a commercially available "ERDAS" software package to compile data for Harvey County, Kansas, Kaplan, Meinhold, Anidu. Hauptmann (1986) developed a GIS aimed at management for Nassau and Suffolk Counties on Long Island. Hendrix and Buckley (1986) used GIS technology for the study of water supply affected by naturally occurring contamination in dolomite aquifers with a high probability of pollution of groundwater by surface activity. The DRASTIC model was already used in many other countries worldwide. It was used for the assessment of groundwater pollution in Anekal Taluk 9n semi-arid area of Bangladore district (Chandrashekhar et al., 1999). Karçoglu's (1999) review groundwater assessment in karst environment. Groundwater vulnerability map has also been prepared in and around Ranchi, Jharkland using the DRASTIC method (Jha et al., 2005). It is computed for the Musi sub-basin from Amberpet to Nallacheruvu in Hyderabad, where there is high DRASTIC index and TDS, hence the groundwater pollution is greater (Anwar et al., 2003).

The identification of the hydrogeological units and subunits as well as the assessment of the DRASTIC parameters, require a good knowledge of the geology, the hydrogeology, the soil media, the topography and the meteorology in the study area (M. H. Hamza et al. 2006).

The DRASTIC method has been designed to provide systematic evaluation of groundwater pollution potential in any hydro geologic setting. DRASTIC consists of several components, the first of which is the designation of mappable hydrogeologic parameters (Aller et al. 1987). These mappable parameters are generally available or can be derived from various sources.

The standard DRASTIC method is based on three components (weight, range and rating) that are expressed numerically. A weight is assigned to each DRASTIC component according to its relative importance to pollution potential. The weight is ranged from five to one with five corresponding to high pollution potential and one to less pollution potential (Aller et al. 1987).

The acronym DRASTIC stands for seven parameters used in the model: Depth to water, net recharge, aquifer media, soil media, topography, impact of vadose zone and hydraulic conductivity. The DRASTIC parameters are divided into range, or significant media types which have an impact on pollution potential (Aller et al. 1987; Ehteshami et al. 1991). Each range for each DRASTIC factor has been evaluated with respect to the others to determine the relative significance of each range to pollution potential (Aller et al. 1987). The rating values vary from one to ten with ten representing the greater pollution potential and one the least.

The DRASTIC index was calculated using the following equation:

Where $\mathrm{R}=$ rating

$$
D_{i}=D_{r} D_{w}+R_{r} R_{w}+A_{r} A_{w}+S_{r} S_{w}+T_{r} T_{w}+I_{r} I_{w}+C_{r} C_{w}
$$

$\mathrm{W}=$ weight

And $\mathrm{D}, \mathrm{R}, \mathrm{A}, \mathrm{S}, \mathrm{T}, \mathrm{I}$ and $\mathrm{C}$ are the seven parameters. The higher the DRASTIC index the greater the groundwater pollution potential.

The seven set of data layers will be processed using ArcGIS 9.2 software in GIS environment. After computing process, the output products are vulnerability maps which show areas that are more likely to be susceptible to groundwater contamination than others. 


\subsection{Regional hydrogeological conditions}

Fen River is the main river flowing throughout Linfen Basin. The hydrogeological condition in the Basin is characterized by an accumulation of thick layers of loose sediments which contain multi-layer groundwater. The layers of loose sediments within the Basin originate from different geologic period and from different types of materials. They form an interlocking deposition with complex lithology and irregular distribution of the aquifer. According to the distribution and hydraulic characteristics of aquifers, the basin can be divided in shallow aquifer, deep aquifer and deep confined aquifer.

The main source of recharge for shallow aquifer is infiltration of rainwater, channel seepage, irrigation return seepage, reservoir seepage and lateral recharge. Discharge is mainly from manual extraction, followed by evapotranspiration. In the middle aquifer, the main source of water supply is from mountain side.

\subsubsection{Aquifer Rock}

Natural and geographical conditions in the area and geological conditions determine the conditions of the basin, groundwater occurrence and distribution. Within the basin, the rocks are loose rock deposits. In mountainous area around the basin, the bedrock is fissured and is constituted by karsts.

\subsubsection{Shallow Aquifer}

The Central part of the basin represents the area where the aquifer is shallow and contains the aquiferous rocks which belong to Pleistocene and the Holocene. The depth to water table is varying from $30-50 \mathrm{~m}$ and the aquifer material is mainly constituted by sand. The water volume is rich. Near the Fen River the depth to water table is $5 \mathrm{~m}$. The edge parts of the basin, mainly piedmonts are alluvial and fluvial material particles which come from the side of mountains into the basin. They gradually change from thin to coarse features. In the edge hill part, there are sands and gravels which gradually turn into fine sand; the clay interlayers appear at the mountain side. Aquifer thickness is higher in mountain side whereas it is smaller inside the basin. The water table with the topography and other condition change. In Fen River where the land is gentle topography has usually depth to water table which does not exceed 5m. Note that in Linfen Basin the depth to water table varies with the season. It is smaller during the rainy season while during the dry season the depth to water table is higher.

In Fenyang Ling, Yang Tan, Quwo and other places, the water table depth is greater than $25-50 \mathrm{~m}$, while in the area of Emei, Taiwan, Wanrong, the depth to water table is greater than $100 \mathrm{~m}$. In most part of Central area the depth to water table varies from 3- $50 \mathrm{~m}$. Depth fluctuating from 3-10m has been located in Longma and Shiraishi areas. 10-30m of depths have been located in the vicinity of Hongdong county and Gansu.

\subsubsection{Depth Aquifer}

The nature of the aquifer rocks originated from different material and makes deep aquifer lithology and thickness quite different. The aquifer rock groups belong to Pleistocene and Holocene alluvial and fluvial sand. The Central part of the Basin has depth to water table fluctuating from 150-200 meters.

In Luliangshan, aquifer rocks are limestone in the mountain side in direct contact with the loose sediments layers. Loose sediment layer which are pluvial are mainly thick with coarse granularity. Generally speaking, there is a good water condition; the eastern mountains have clastic sedimentary rock and loose sedimentary layer. The grains size is fine and the aquifers are almost non-inexistent.

For river and lake basin accumulation phase, grain particle sizes are smaller but the thickness is large to allow good storage condition. The water table in Huo, Xian in the East of the piedmont inclined plain varies from $80-100 \mathrm{~m}$. In the North of Linfen Village area, the depth to water table is from 50-100m. Xinjiang to West Heijin tilt between the plain and the Piedmont Plateau Emei. The depth to water table is varying from $50-100 \mathrm{~m}$. In the High Plateau the depth is greater than 100 meters.

\subsubsection{The depth Confined aquifer}

The depth confined aquifer materials originate from Pleistocene and Tertiary. The depths to water table vary from $350-400 \mathrm{~m}$. The roof depths are from $150-200 \mathrm{~m}$. Because we are studying the vulnerability of unconfined and shallow aquifer we have assigned a rating of 0 to area where the water table is greater than 100 and where the aquifer is confined.

\section{Assessment of aquifer vulnerability with the DRASTIC model}

Groundwater vulnerability in Linfen Basin is evaluated using hydro geologic parameters that can affect the contaminants transport through the vadose zone to the water table using DRASTIC (Aller et al. 1987). DRASTIC model which is an overlay/index method (Vrba and Zaporotec, 1994; USEPA, 1993; Zhang et al., 
1996) was developed by US/ EPA to be the standardized method for groundwater vulnerability assessment. DRASTIC can be categorized into 2 steps: (1) hydrogeology setting classification and (2) scoring method (Ckakraborty S et al., 2007).

The DRASTIC method uses the system of weight and rating. The different parameters are weighted according to their relative importance in the determination of the capability of contaminants to reach an aquifer. The weight of hydro geologic setting used in DRASTIC varies from 1 to 5 , where 1 represent the least factor and 5 represent the most significant factor in groundwater pollution potential. The DRASTIC method assumes that all the contaminants moves vertically downward with the water and that they are introduced at the soil surface (Ckakraborty S et al., 2007).

As for ratings, they reflect the relative significance of classes which vary from 1 to 10 within each of the seven parameters.

\subsection{Data layer preparation}

The hydrogeologic settings which are utilized in DRASTIC methodology to carry out the aquifer vulnerability assessment in Linfen Basin, Northern China are:

3.1.1 Depth to water (D): It represents the depth from ground surface to water table. It is an important factor because it determines the depth of materials through which contaminants must pass before reaching the water table. It also affects the time available for contamination to undergo chemical and biological reactions such as dispersion, oxidation, natural attenuation, sorption etc. (Ckakraborty S et al., 2007). Hence, the deeper the depth to water table the lesser the chance of pollutants to arrive to the water table and the greater for pollutants to be attenuated.

The information concerning the depth to water table was collected from borehole data obtained from the Chinese Geological Investigation Bureau of Shanxi Province. According to data collected, the depth varies from $1.50 \mathrm{~m}$ to $600.37 \mathrm{~m}$. In assigning rating for each range, beyond $100 \mathrm{~m}$ we have assumed that the probability for pollutants to reach groundwater is quasi null because of attenuation process of filtration, biodegradation, sorption, and volatilization (Aller et al.1987). Then we assign the rating of 0 . The range and rating used for depth to water table is akin to the one utilized by Dhundi RP et al., (2008) which in fact is the converted version of the standard rating for depth to water according to Aller et al., (1987). The values for range and rating are presented in table 1 and the depth to water map is showed in fig 2 .

3.1.2 Recharge (R): Groundwater recharge or deep drainage or deep percolation is a hydrologic process where water moves downward from surface water to groundwater. Net recharge represents the annual average amount of water that infiltrates the vadose zone and reaches the water table (Aller et al. 1987). Net recharge is an agent which can easily transport contaminant to groundwater. Then the greater the recharge, the more vulnerable is the aquifer to contamination because its controls the volume of water available for dispersion and dilution of the contaminants in the vadose zone.

The main source of groundwater recharge is precipitation which percolates from the ground surface and infiltrates through the soil and the unsaturated zone to reach the aquifer. Sources of recharge may include precipitation, irrigation, and wastewater whereas discharge areas may include springs and rivers.

In the study area, local recharge is inflow from the Fen River and its tributaries, irrigation return flow and direct recharge. The data of recharge was obtained from the hydro geological report (Linfen Groundwater Resource Investigation). The average direct annual volume of recharge into the aquifer from the Fen River is $889104 \mathrm{~m}^{3} /$ year. The recharge map (fig3) was obtained by interpolating annual recharge rate because of the lack of some data needed in the evaluation of the net recharge. As previously mentioned, Linfen Basin is located in semi arid region which is characterized by low amount of the annual precipitation. Therefore, the rating values from 1 to 4 were assigned to net recharge. High value was assigned to area with high recharge rate and low value to areas with low recharge rate.

3.1.3 Aquifer media (A): An aquifer is a subsurface rock or sediment unit that will yield usable quantities of water to a well or spring (Heath, 1987). It plays an important role on attenuation capacity of pollutants. Aquifer media designates the consolidated and unconsolidated rocks which serve as an aquifer. The contaminant attenuation in an aquifer media depends on the amount and size of fine grains. Lower the grains size, higher will be the attenuation capacity of aquifer media. Aquifer media governs the route and path length within the aquifer. The path length determines the time available for attenuation process (Piscopo G, 2001). The aquifer media data has been obtained from more than 200 boreholes, using a subsurface geology map and report on Linfen Basin 
groundwater numerical simulation research (Tang et al. 2006, in Chinese). The aquifer media parameter has been presented in table 2 and the data computation result has given the map represented in fig4.

3.1.4 Soil media (S): Characterized by important biological activities, soil media represents the uppermost portion of the vadose zone. It has an impact on the amount of recharge that infiltrates into the groundwater, then influence the surface and downward movements of the pollutants. It finally exerts an important role on the purifying process of contaminants. In general, soil pollution potential is affected largely by the type is affected by the type and amount of clay present, the shrink/swell potential and the grain size (Aller et al,. 1987). The less the clay shrink and swells and the smaller the grain size, the less the pollution potential (Aller et al,. 1987).

The soil media types were then assigned ratings from 1 to 10 according to their permeability. Coarse soil media have high rates in comparison to fine soil media. The rating and index used to map the parameter soil media is shown is table 3 and the fig 5 represents the soil map.

3.1.5 Topography (T): It refers to the slope variability of an area. Topography controls the likelihood that rainfall and pollutants have to run-off or to be retained in one area long enough to infiltrate. Areas with low slope (0-2\%) tend to retain water for longer, hence provide a greater infiltration of recharge water which may contains considerable amount of pollutants whereas area with steeper slope $(+18 \%)$ has little potential exist for recharge, then pollutants have little opportunity to reach the groundwater. Topography influences soil development and therefore has an effect on attenuation (Aller et al,. 1987).

The digital elevation model of Linfen was used to extract topography value (altitude) of the area. In Linfen Basin, the highest altitude is $1890.30 \mathrm{~m}$ at Orphaned Mountain. The terrains lean from Northeast to Southwest. Topography data have been obtained from digital map. Slope was then classified and ranked from 1 to 10 for use in the topography map component. Table 4 shows the rating used to build topography map (fig6).

3.1.6 Impact of vadose zone (I): It designates the ground portion between the water table and the soil media (unsaturated zone). It influences aquifer pollution potential like soil cover depending on the permeability of the media. If vadose zone is highly permeable, then this will lead to a high vulnerable rating (Corwin, et al., 1997). Vadose zone is also the place where biodegradation, neutralization, mechanical filtration, chemical reaction, volatilization and dispersion are processes which may occur within the vadose zone (Aller et al,. 1987). Finally the type of vadose zone determines the attenuation characteristic of the material below the typical soil horizon and above the water table (Aller et al,. 1987). The vadose zone map (fig 7) has been generated from borehole data (table 5).

3.1.7 Hydraulic conductivity $(\mathrm{C})$ : It expresses the ability of the aquifer materials to transmit water, which in turn controls the rate at which groundwater will flow under a given hydraulic gradient. It also controls the contaminants movement rate in the aquifer. Therefore, aquifer vulnerability is related to hydraulic conductivity through the aquifer's capacity to transport pollutants away from the point at which they enter the aquifer (Ckakraborty S et al,. 2007). An aquifer with high hydraulic conductivity is more vulnerable to potential contamination than an aquifer with low conductivity.

According to the Linfen Basin borehole data the lithology are grouped into 5: gravel- bedrock, gravel bed and sand, sandy-gravel, sand, clayey-gravel (Shanxi Province Water Resource Evaluation Report).

From data obtained according to lithology of boreholes and section plan, the equivalent thickness method of each layer is given as:

$\mathrm{K}_{1} \mathrm{M}_{1}+\mathrm{K}_{2} \mathrm{M}_{2}+\ldots \ldots \ldots \ldots \ldots \mathrm{K}_{\mathrm{N}} \mathrm{M}_{\mathrm{N}}=\mathrm{K}\left(\mathrm{M}_{1}+\mathrm{M}_{2}+\ldots \ldots \ldots . . \mathrm{M}_{\mathrm{N}}\right)$

Where $\mathrm{K}_{1}, \mathrm{~K}_{2}, \mathrm{~K}_{\mathrm{N}}$ are different lithology hydraulic conductivity and $\mathrm{M}_{1}, \mathrm{M}_{2}$, and $\mathrm{M}_{\mathrm{N}}$ are the corresponding layer thickness.

The mean hydraulic conductivity per range varies from: 3.38/d for sand, 6.19/d for sandy- gravel, 13.47/d sand-gravel, 108/d gravel and $0.83 / \mathrm{d}$ for sand-gravel-clay respectively. Table 6 shows the range and rating for hydraulic conductivity (fig8)

\subsection{The aquifer vulnerability map}

The DRASTIC index for the given area is calculated by multiplying each parameter's ratings by the assigned weights that reflect the relative contribution of each factor to the contamination process in general. The final vulnerability map was obtained by running the model in the ArcGIS 9.2 software in GIS environment by using the seven hydro-geological data layers.

The DRASTIC indices were first classified into ranges by imposing arbitrary thresholds. 
The DRASTIC scores obtained from the model vary from 59 to 147 , where the higher value implies the relative greater vulnerability. These values were reclassified into three classes using the quantile classification scheme i.e., very low vulnerable zones, low vulnerable zones and moderate vulnerable zones. The vulnerability scores are presented based on the classification scheme introduced by Aller et al. (1987). According to the results of the groundwater vulnerability assessment (fig9), the study area can be divided into three zones: very low groundwater vulnerability risk zone (risk index $<79$ ); low groundwater vulnerability risk zone (risk index 80 119 ), and moderate vulnerability zone (risk index 120-150).

Under the natural condition, the moderate vulnerability zones of Linfen Basin are located in the north and southeastern part of the basin. The moderate vulnerable zones cover around $16.38 \%$ of the study area. Huozhou City in the north, Yicheng County, Qu Wo County in the south east are concerned by moderate vulnerability zones.

The very low vulnerable zones are well distributed and are mainly located in the middle and south parts of the basin. Some very low vulnerable zones can also be seen in the north east and extreme east parts. Very low vulnerable zones cover about $40.13 \%$ of the study area. The remaining parts of the Linfen basin are under low vulnerable zones (43.43\%) which are located in the west and Middle West parts of the region.

\section{Sensitivity analysis}

GW vulnerability monitoring using DRASTIC model utilizes seven hydro-geological parameters which are believed to affect the transport of the contaminants to the aquifer. The high number of input parameters is supposed to reduce the impact of errors or uncertainties of the individual parameter on the final output (Rosen, 1994). However, some scientists argued that GW vulnerability assessment may be implemented without using all the parameters of the DRASTIC model (Barber et al. 1993; Merchant, 1994). Moreover, the subjectivity associated with the selection of the seven parameters, the ratings, and the weights used to compute the vulnerability index has also been criticized (Napolitano and Fabbri, 1996) and lead to the conclusion that there is a reason to doubt the accuracy of the vulnerability assessment result. Indeed, many factors influence the result of the model such as the type of overlay operation performed, the value of the weights, the number of data layers and map units in each layer, the error or uncertainty associated to each map unit etc.. (Ckakraborty, 2007; A. Rahman, 2008).

Sensitivity tests were used as supporting experimental evidence for DRASTIC model implementation to remove the doubt about the accuracy of the model.

Two (2) sensitivity tests were then carry out: the map removal sensitivity analysis (Lodwick et al. 1990) and the single parameter sensitivity test (Babiker et al. 2005).

The map removal sensitivity analysis determines the sensitivity of vulnerability map by removing one or more layer map and is implemented using the following equation:

$\mathrm{S}=\left(\left|\mathrm{V} / \mathrm{N}-\mathrm{V}^{\prime} / \mathrm{n}\right| / \mathrm{V}\right) \times 100$,

Where $\mathrm{S}$ is the sensitivity measure, $\mathrm{V}$ and $\mathrm{V}^{\prime}$ are the unperturbed and the perturbed vulnerability indices respectively, and $\mathrm{N}$ and $\mathrm{n}$ are the number of data layers used to compute $\mathrm{V}$ and $\mathrm{V}$. The unperturbed vulnerability index is the actual index obtained by using all the seven parameters and the perturbed vulnerability index used the lower number of parameters during computation processing.

The single parameter sensitivity analysis is used to assess the influence of each of the seven parameters of the model on the vulnerability measure. In this analysis real or effective weight of each parameter is compared with the assigned or theoretical weight. The effective weight of a parameter is calculated using the following equation:

$\mathrm{W}=(\mathrm{Pr} \mathrm{Pw} / \mathrm{V}) \times 100$

$\mathrm{W}=$ effective weight of the parameter

$\operatorname{Pr}=$ Rating

$\mathrm{Pw}=$ Weight

$\mathrm{V}=$ Vulnerability index

The table 7 presents the statistical summary of the seven DRASTIC parameters maps used to implement aquifer vulnerability at Linfen Basin. According to the statistical result of means which can be seen in the table 9, the highest risk of contamination of GW originates from the topography with a mean value of $8.73 \%$. The $2^{\text {nd }}$ risk rank of GW vulnerability to contamination is detained by impact of vadose which has a mean value of $5.50 \%$. It 
is closely followed by the aquifer media zone with a mean value of $5.28 \%$. The fourth place is occupied by soil media layer $(4.88 \%)$ closely followed by net recharge (3.93\%). The depths to water table $(1.97 \%)$ and hydraulic conductivity $(1.85 \%)$ provided the least mean value for their contribution to GW contamination in the study area.

The coefficient of variation indicates that the highest contribution to the vulnerability index is provided by depth to water table and net recharge map parameters with values of 46.19 and $25.95 \%$ respectively. The soil media zone parameter is the third in importance with a value of $18.44 \%$. Moderate contribution in the coefficient of variation is made by conductivity map (15.67\%) and impact of vadose zone map (11.09\%) parameters while the lowest variation comes from topography map (6.75\%). The low variability of the parameter signifies a smaller contribution to the variation of the vulnerability index across the study area.

\subsection{Map removal sensitivity analysis}

The results of the map removal sensitivity analysis computed by removing one or more data layers at a time are presented in tables 8 and 9 .

The first map removal sensitivity analysis table describes the variation of the vulnerability index as a result of removing only one layer at a time. The study does not show a very clear variation in the vulnerability index because of removing only one layer at a time. In general the mean variation does not exceed $1 \%$. Then the mean variation indexes are much closed to each other. However, the highest variation of the vulnerability index is expected upon the removal of the impact of vadose zone parameter from the computation. This parameter shows a high relative mean value of variation index $(2.55 \%)$ when removed from the computation. This could be mainly attributed to the relatively high theoretical weight assigned to this layer and the characteristic of the material which composed the aquifer at Linfen Basin. The variation of vulnerability index seems to be also relatively sensitive to the removal of hydraulic conductivity layer from the computation. With a mean variation index of $1.38 \%$ it is the $2^{\text {nd }}$ in importance according to the result of single parameter sensitivity analysis. For the remaining parameters, their removal from the computation during the map removal sensitivity analysis involves a small variation in the mean vulnerability index. As it can be seen in table 11, the variation index varies from $0.47 \%$ to $0.87 \%$.

In the second map removal sensitivity analysis, the variation of the vulnerability index is due to the removal of one or more parameters at a time from the model computation. The results of this $2^{\text {nd }}$ map removal sensitivity analysis are shown in table 11. The removal of the parameters was based on the first map removal sensitivity measure (table11). As usually when doing map removal sensitivity measure, the parameters which play less variation on the final vulnerability index, were preferentially removed first and then next lesser and so on (I.S Babiker et al. 2005; A. Rahman, 2008). The least mean variation index has resulted after removing only the aquifer media layer $(0.47 \%)$ from the model computation. As more data layers are excluded from the computation of the vulnerability index, the mean variation index increases. Although the layers assumed to be the most effective were considered each time, the interpretation of the growing average is not clear. It might partly be attributed to one or more of the following reasons: the internal variation of the individual parameter, the weights assigned to them, and their weak representation of the real world (I.S Babiker et al. 2005). Conclusively, considerable variation in the vulnerability assessment is not expected in this case study if a lower number of data layers have been used.

\subsection{Single parameter sensitivity analysis}

The map removal sensitivity analysis has revealed the significance of the seven parameters in the vulnerability assessment in the previous section.

Herein, we are applying the single parameter sensitivity analysis in order to compare their "effective weight" with their "theoretical weight". The effective weight is a function of the value of the single parameter with regard to the other six parameters as well as the weight assigned to it by the DRASTIC model (Babiker 2005, A. Rahman, 2007). In the single parameter sensitivity analysis (table 10), we can see that there are some deviations from the effective weight when compared to the theoretical weight. The impact of vadose zone $(29.57 \%)$ and the aquifer media $(17.08 \%)$ are the most effective parameters in this vulnerability assessment because of their effective weight is largely greater than their theoretical weight (21.7 and 13\% respectively). The topography parameter $(9.48 \%)$ and soil media $(10.50 \%)$ also show high effective weight in comparison to their theoretical weight ( $4.3 \%$ and $8.7 \%$ respectively). The remaining parameters, in contrary, exhibited lower effective weight.

The importance of the impact of vadose zone, aquifer media, topography and soil media parameters due to the significance of their effective weight obtained from the single parameter sensitivity analysis highlight the necessity of getting more accurate data and detailed information about these parameters. Finally, the deep aquifer 
in Linfen Basin area contributes to minimize the importance of the depth to water table parameter in this groundwater vulnerability assessment.

\section{Groundwater Contamination Analysis}

The purpose of these analyses is to find out whether there is a relationship between the intrinsic vulnerability assessment result and groundwater contamination at Linfen Basin. Concentration of contaminants in groundwater was evaluated for validation of the DRASTIC results. Whereas groundwater intrinsic vulnerability assessment indices vary from low to moderate potential pollution, then lower vulnerability to potential contamination of the aquifer, groundwater sample collected from 222 wells after analysis mainly exhibited high level of groundwater pollution which exceeds the standard level allowed by the WHO (World Health Organization) and Chinese standard for drinking water.

Groundwater quality analysis was conducted under Linfen Groundwater Resource Investigation project in 2006. Samples have been taken at different locations throughout the basin for analysis. These samples have been measured for the total hardness (CaCO3), TDS, PH, So42, No2-, No3-, NH4+, F-, Hg, Cr6+ etc. High total hardness and TDS and high concentration of chemical elements beyond their permissible limits have been found in groundwater. This is mainly due to anthropogenic activities. Linfen is well known to be among the most polluted city in China because of its industrial activity.

Water quality at Linfen has been classified according to Chinese water quality standard with the range varying from very bad to very good. Table 12 presents the result of groundwater quality analysis for 222 samples collected throughout Linfen Basin.

The groundwater sample analysis result (fig 10) shows that $29.72 \%$ of the samples are very bad quality and $43.24 \%$ are relatively bad quality whereas $27.02 \%$ are related to sample with good quality. In fact, $72.96 \%$ of the water samples collected vary from relatively bad to very bad. Very bad quality of water has been found at 66 different locations throughout the study area. The worst quality is found at Wang Cun Fen He Shui with 7.92 $\mathrm{mg} / \mathrm{L}$ of pollutants concentration in groundwater whereas the good quality has been found at Feng Zheng. Therefore, water quality is a serious concern in Linfen Basin and action must be undertaken to stop groundwater quality degradation so that public health can be safe.

\section{Conclusion}

Linfen Basin, located in Shanxi Province, northern China, is a semi arid region where groundwater plays an important role in water supply. Excessive abstraction and anthropogenic activities have altered groundwater quality in the study area. This study utilized DRASTIC model and GIS technique to assess the aquifer vulnerability at Linfen Basin. Seven environmental parameters which include Depth to water, net Recharge, Aquifer media, Soil media, Topography, Impact of vadose zone, and hydraulic Conductivity were used to represent the hydro geological setting of Linfen Basin. The result of groundwater vulnerability assessment shows index values which vary from 59 to 147 . According to the results of the groundwater vulnerability assessment, the study area has been divided into three zones: very low groundwater vulnerability risk zone (risk index $<79$ ); low groundwater vulnerability risk zone (risk index 80-119), and moderate vulnerability zone (risk index 120 150).

The result of groundwater contamination analysis shows that the aquifer is polluted although the intrinsic vulnerability assessment of the Linfen Basin presents groundwater resources as less sensitive or less vulnerable to potential contamination. This indicates that the obtained results from the intrinsic vulnerability assessment are not realistic and not representative to the actual situation in the field. Groundwater at Linfen area can be a threat for public health if serious action is not taken to stop further pollution.

\section{Acknowledgments}

The authors are thankful to Chinese Scholarship Council (CSC), China University of Geosciences (CUG) for their financial support. Special thanks go to Prof. Tang Zhonghua for his guidance during the researches and to Mr. Gary Reece who despite his multitude occupations has accepted to read the manuscript.

\section{References}

Aller L, Bennet T, Lehr HJ, Petty JR, Hackett G. (1987). DRASTIC: a standardized system for evaluating groundwater pollution potential using hydrogeologic settings. EPA-600/2-87-035, 1987. 622.

Amanda LB. (2006). Groundwater Vulnerability to potential Contamination in the Annapolis Valley, Nova Scotia. PhD thesis, Acadia University. 
Anwar, Prem, \& Rao, M. Anwar, C.C. Prem and V.B. Rao. (2002). Evaluation of groundwater potential of Musi River catchment using DRASTIC index model. In: B.R. Venkateshwar, M.K. Ram, C.S. Sarala and C. Raju, Editors, Hydrology and watershed management. Proceedings of the international conference 18-20, 2002, B. S. Publishers, Hyderabad (2003), pp. 399-409.

Atkinson, S et al. (1994). An examination of groundwater pollution potential through GIS modeling. ASPRS/ACSM.

Babiker IS, Mohammed MAA, Hiyama T, \& Kato K. (2005). A GIS-based DRATIC model for assessing aquifer vulnerability in Kakamigahara Heights, Gifu Prefecture, central Japan. Sci Total Environ 2005; 345: 127-140.

Chandrashekhar H, Adiga S, Lakshminarayana V, Jagdeesha CJ, Nataraju C. (1999). A case study using the model 'DRASTIC' for assessment of groundwater pollution potential. In Proceedings of the ISRS national symposium on remote sensing applications for natural resources. June, 1999: 19-21, Bagalore.

Ckakraborty, S. (2007). Assessing aquifer vulnerability to arsenic pollution using DRASTIC and GIS of North Bengal Plain: A case study of English Bazar Block, Malda District, West Bengal, India, Vol.7, No.1, Springer 2007.

Doerfliger N, Zwahlen F. (1997). EPIK: A new method for outling of protection areas in karstic environment. In: International symposium on karst waters and environmental impacts, 1997:117-123.

El-Naqa A. (2004). Aquifer vulnerability assessment using the DRASTIC model at Russeifa landfill, northeast Jordan. J Environ Geol 2004:47(1):51-62.

Fritch TG, McKnight CL, Yelderman Jr JC, \& Arnold JG. (2000). An aquifer vulnerability assessment of the paluxy aquifer, central Texas, USA, using GIS and a modified DRASTIC approach. Environ Manage 2000; 25:337-345.

Gogu RC, Dassargues A. (2000). Sensitivity analysis for the EPIK method of vulnerability assessment in a small karstic aquifer, Southern Belgium. Hydrogeol J 2000; 8(3):337-345.

Guo H, Wang Y. (2004). Specific vulnerability assessment using the MLPI model in Datong city, Shanxi province, China. Environ Geol; 45:401-407.

Hamerlinck JD, Ameson CS. (1998). (eds) Wyoming Groundwater vulnerability assessment handbook, Vol I. University of Wyoming, SDVC Report, 98-01-1, pp 31-62.

Hearne, G et al. (1992). Vulnerability of the uppermost groundwater to contamination in the greater Denver Area, Colorado. USGS water resources investigation report 92-4143, $241 \mathrm{pp}$.

Heat, R.C. (1987). Basic Groundwater Hydrology. US Geological Survey Water Supply paper 2220, U.S. Department of the Interior, US. Geological Survey.

Hendrix W.G et al. (1986). Geographic information system technology as a tool for groundwater management., Vol3. Fall church: American Society of Photogrammetric and Remote Sensing, pp. 230-239

Kalinski, R et al. (1994). Correlation between DRASTIC vulnerabilities and incidents of VOC contamination of municipal wells in Nebraska. Groundwater, 32(1), 31-34

Li YM. (2001). Environmental chemistry study of waterborne poisoning in Shanyin, Shanxi province. MS. Thesis, China University of Geosciences, Wuhan, P.R. China (In Chinese, with English Abstract).

Lodwik WA, Monson W, Svoboda L. (1990). Attribute error and sensitivity analysis of maps operation in geographical information systems-suitability analysis. Int J Geograph Inf Syst; 4:413-428.

Lynch SD, Reynders AG, \& Schulze RE. (1994). Preparing input data for a national-scale groundwater vulnerability map of southern Africa. Document ESRI 94.

M.H. Hamza. (2006). A GIS-based DRASTIC vulnerability and net recharge reassessment in an aquifer of a semi-arid region (Metline-Ras Jebel-Raf Raf aquifer, Northern Tunisia.

Margat, J. (1968). Vulnérabilité des nappes d'eau souterraine à la pollution [Groundwater vulnerability to contamination]. Bases de la cartographie, (Doc.) 68 SGC 198 HYD, BRGM, Orleans, France.

Merchant JW. (1994). GIS-based groundwater Pollution hazard assessment a critical review of the DRASTIC model. Photogramm Eng Rem S; 60(9):1117-1127. 
Napolitano P, Fabbri AG. (1996). Single parameter sensitivity analysis for aquifer vulnerability assessment using DRASTIC and SINTACS. In: Proceedings of the 2nd HydroGIS conference. IAHS Publication, Wallingford; 235:559-566.

National Research Council Groundwater vulnerability assessment. (1993). Contamination potential under conditions of uncertainty, National Academy Press, Washington, DC.

Piscopo, G. (2001). Groundwater Vulnerability Map Explanatory Notes - Castlereagh Catchment. Parramatta NSW: Australia NSW Department of Land and Water Conservation.

Ramos-Leal JA, Rodríguez-Castillo R. (2003). Aquifer vulnerability mapping in the Turbio river valley, Mexico, a validation study. Geofisica Int; 42(1):141-156.

Rosen, L. (1994). Study of the DRASTIC methodology with the emphasis on Swedish conditions. $37^{\text {th }}$ conference of the International Association for Great Lakes Research and Estuaire Research Federation. Buffalo, p. 166

Rundquist, D et al. (1991). Statewide groundwater vulnerability assessment in Nebraska using DRASTIC/GISmodel. Geocarto International, 2 Hong Kong.

Said Ettazarini. (2006). Groundwater pollution risk mapping for the Eocene aquifer of Oum Er-Rabia basin, Morocco, Springer Journal DOI 10.1007/s00254-006-0330-1

Venkataramanan B. (2000). Use of WHPA and DRASTIC models in vulnerability assessment of aquifers on GIS platform, University of Madras, Chennai, India.

Vrba J, Zaporozec A. (1994). Guidebook on mapping groundwater vulnerability, international contributions to hydrology. Heinz Heise, Hannover; 16: 131.

Wang JH. (1998). Endemic arseniasis and endemic fluorosis and regional environmental geochemical research in Datong basin, Shanxi province. PhD Thesis, China University of Geosciences, Beijing, P. R. China (In Chinese, with English Abstract).

Wang JH, Zhao LS, Wu YB. (1998). Environmental geochemical study on arsenic in arseniasis areas in Shanyin and Yingxian, Shanxi Province. Geosciences (In Chinese with English Abstract);12 (2), 243-248.

Wang Y, Ma T, Luo Z. (2001). Geostatistical and geochemical analysis of surface water leakage into groundwater on a regional scale: a case study in the Liulin karst system, northwestern China. $J$ Hydrol; 246:223-234.

Wang Y, Stepan LS, Su C. (2008). Genesis of arsenic/fluoride-enriched soda water: a case study at Datong, northern China. App Geochem. In press.

Zhang R, Hamerlinck JD, Gloss SP, Munn L. (1996). Determination of nonpoint source pollution using GIS and numerical models. J Environ Qual; 25(3):411-418.

Table 1. Range and Rating for Depth to Water

\begin{tabular}{ccc}
\hline Range $(\mathrm{m})$ & Rating & Index \\
\hline$\leq 1.5$ & 10 & 50 \\
$1.6-4.6$ & 9 & 45 \\
$4.6-9.1$ & 7 & 35 \\
$9.1-15.2$ & 5 & 25 \\
$15.2-22.5$ & 3 & 15 \\
$22.5-30$ & 2 & 10 \\
$\geq 30$ & 1 & 5 \\
\hline
\end{tabular}

Weight: 5 
Table 2. Range and Rating for Aquifer Media

\begin{tabular}{ccc}
\hline Range & Rating & Index \\
\hline Fine Sand & 4 & 12 \\
Medium Sand & 6 & 18 \\
Coarse Sand & 8 & 24 \\
Gravel and Sand & 9 & 27 \\
Gravel & 10 & 30 \\
\hline
\end{tabular}

Weigth: 3

Table 3. Range and Rating for soil media

\begin{tabular}{ccc}
\hline Range & Rating & Index \\
\hline Gravel & 10 & 20 \\
Sand & 9 & 18 \\
Sandy loam & 6 & 12 \\
Loam & 5 & 10 \\
Silty-loam & 4 & 8 \\
Clay-loam & 3 & 6 \\
\hline
\end{tabular}

Weight: 2

Table 4. Range and Rating for Topography

\begin{tabular}{|c|c|c|}
\hline Range & Rating & Index \\
\hline $0-2$ & 10 & 10 \\
\hline $2-4$ & 9 & 9 \\
\hline $4-6$ & 8 & 8 \\
\hline $6-8$ & 7 & 7 \\
\hline $8-10$ & 6 & 6 \\
\hline $10-12$ & 5 & 5 \\
\hline $12-14$ & 4 & 4 \\
\hline $14-16$ & 3 & 3 \\
\hline $16-18$ & 2 & 2 \\
\hline$>18$ & 1 & 1 \\
\hline
\end{tabular}

Weight: 1 (Source Ckakraborty S et al. 2007)

Table 5. Range and rating for vadose zone

\begin{tabular}{ccc}
\hline Range & Rating & Index \\
\hline Clay and Silt & 3 & 15 \\
Sandy/ Clay & 4 & 20 \\
Clay Sand & 6 & 30 \\
Sand and Gravel & 8 & 40 \\
\hline
\end{tabular}

Weight: 5 
Table 6. Range and Rating for hydraulic conductivity

\begin{tabular}{ccc}
\hline Range & Rating & Index \\
\hline $0-5$ & 1 & 3 \\
$5-15$ & 2 & 6 \\
$15-30$ & 4 & 12 \\
$30-50$ & 7 & 21 \\
$50-70$ & 8 & 24 \\
$70-90$ & 9 & 27 \\
$>90$ & 10 & 30 \\
\hline
\end{tabular}

Weight $=3$

Table 7. Statistical summary of the seven parameters

\begin{tabular}{cccccccc}
\hline & $\mathrm{D}$ & $\mathrm{R}$ & $\mathrm{A}$ & $\mathrm{S}$ & $\mathrm{T}$ & $\mathrm{I}$ & $\mathrm{C}$ \\
\hline Min & 1 & 1 & 3.45 & 1 & 5.01 & 2.81 & 1 \\
Max & 10 & 6 & 10 & 10 & 9 & 10 & 2 \\
Mean & 1.97 & 3.93 & 5.28 & 4.88 & 8.73 & 5.50 & 1.85 \\
SD & 0.91 & 1.02 & 0.44 & 0.90 & 0.59 & 0.61 & 0.29 \\
CV & 46.19 & 25.95 & 8.33 & 18.44 & 6.75 & 11.09 & 15.67 \\
\hline
\end{tabular}

Table 8. Map removal sensitivity analysis

\begin{tabular}{ccccc}
\hline $\begin{array}{c}\text { Parameters } \\
\text { removed }\end{array}$ & Variation & Index (\%) & & \\
\hline D & Minimum & Maximum & Mean & S.D \\
\hline R & 0 & 4.18 & 0.89 & 0.38 \\
$\mathrm{~A}$ & 0 & 2.83 & 0.61 & 0.48 \\
$\mathrm{~S}$ & 0 & 1.28 & 0.47 & 0.15 \\
$\mathrm{~T}$ & 0 & 1.97 & 0.63 & 0.30 \\
$\mathrm{I}$ & 0.1 & 1.67 & 0.80 & 0.19 \\
$\mathrm{C}$ & 0.61 & 4.19 & 2.55 & 0.34 \\
\hline
\end{tabular}

One parameter is removed

Table 9. Map removal sensitivity analysis

\begin{tabular}{ccccc}
\hline Parameters used & Variation & Index $(\%)$ & & \\
\cline { 2 - 5 } & Min & Max & Mean & S.D \\
\hline DRSTIC & 0 & 1.28 & 0.47 & 0.15 \\
DSTIC & 0 & 3.40 & 1.10 & 0.64 \\
DTIC & 0 & 3.73 & 0.96 & 0.51 \\
DIC & 0 & 7.92 & 1.25 & 1.25 \\
IC & 0 & 7.54 & 3.50 & 1.10 \\
I & 3.67 & 25.14 & 15.29 & 2.04 \\
\hline
\end{tabular}

One or more parameters are removed at a time 
Table 10. Single parameter sensitivity analysis

\begin{tabular}{ccccccc}
\hline \multirow{2}{*}{ Parameters } & $\begin{array}{c}\text { Theoretical } \\
\text { Weight }\end{array}$ & $\begin{array}{c}\text { Theoretical } \\
\text { weight (\%) }\end{array}$ & $\begin{array}{c}\text { Effective } \\
\text { weight (\%) }\end{array}$ & & & \\
\cline { 3 - 6 } & & 21.7 & 10.55 & 4.46 & 39.37 & 4.46 \\
\hline D & 5 & 17.4 & 16.83 & 4.58 & 31.25 & 3.90 \\
R & 4 & 13.0 & 17.08 & 12.38 & 21.97 & 0.92 \\
A & 3 & 8.7 & 10.50 & 2.46 & 15.83 & 1.82 \\
S & 2 & 4.3 & 9.48 & 4.25 & 13.68 & 1.12 \\
T & 1 & 21.7 & 29.57 & 17.96 & 39.42 & 2.04 \\
I & 5 & 13.0 & 5.99 & 2.71 & 9.52 & 1.01 \\
C & 3 & & & & & Minimum \\
\hline
\end{tabular}

SD refers to standard deviation.

Table 11. Area under different groundwater vulnerability to contamination in Linfen Basin

\begin{tabular}{cccc}
\hline Model Index Value & $\begin{array}{c}\text { Vulnerability Category } \\
\text { Index Rating }\end{array}$ & Area (in \%) & $\begin{array}{c}\text { Description of relative } \\
\text { vulnerability }\end{array}$ \\
\hline $1-79$ & 1 & 40.13 & Very low \\
$80-119$ & 2 & 43.49 & Low \\
$120-150$ & 3 & 16.38 & Moderate \\
\hline
\end{tabular}

Table 12. Groundwater quality analysis result

\begin{tabular}{ccc}
\hline $\begin{array}{c}\text { Concentration of Contaminant } \\
(\mathrm{mg} / \mathrm{L})\end{array}$ & Indication & Location \\
\hline 0.08 & Very good & - \\
$08-2.50$ & Good & 60 \\
$2.50-4.25$ & Relatively good & - \\
$4.25<7.20$ & Relatively bad & 96 \\
$>7.20$ & Very bad & 66 \\
& & $\mathbf{2 2 2}$ \\
\hline
\end{tabular}




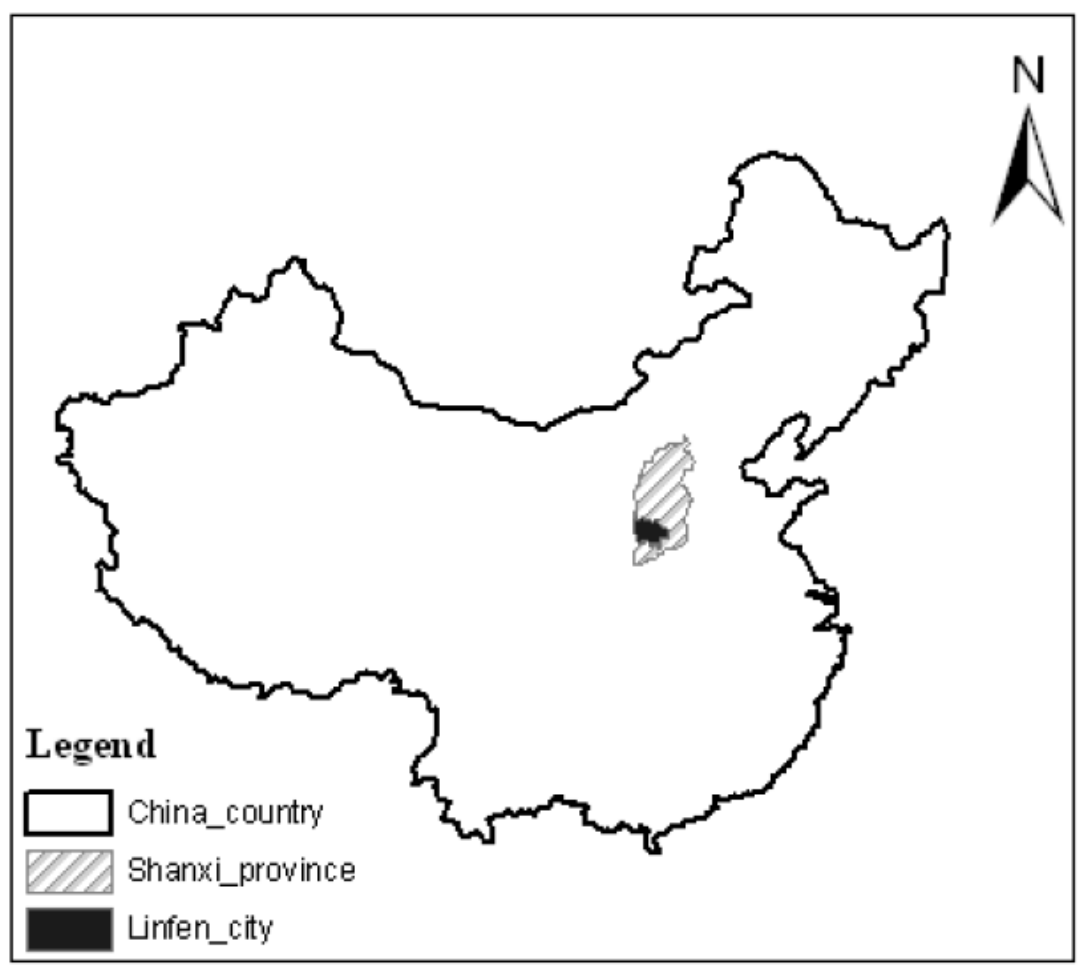

Figure 1. Location of the study area

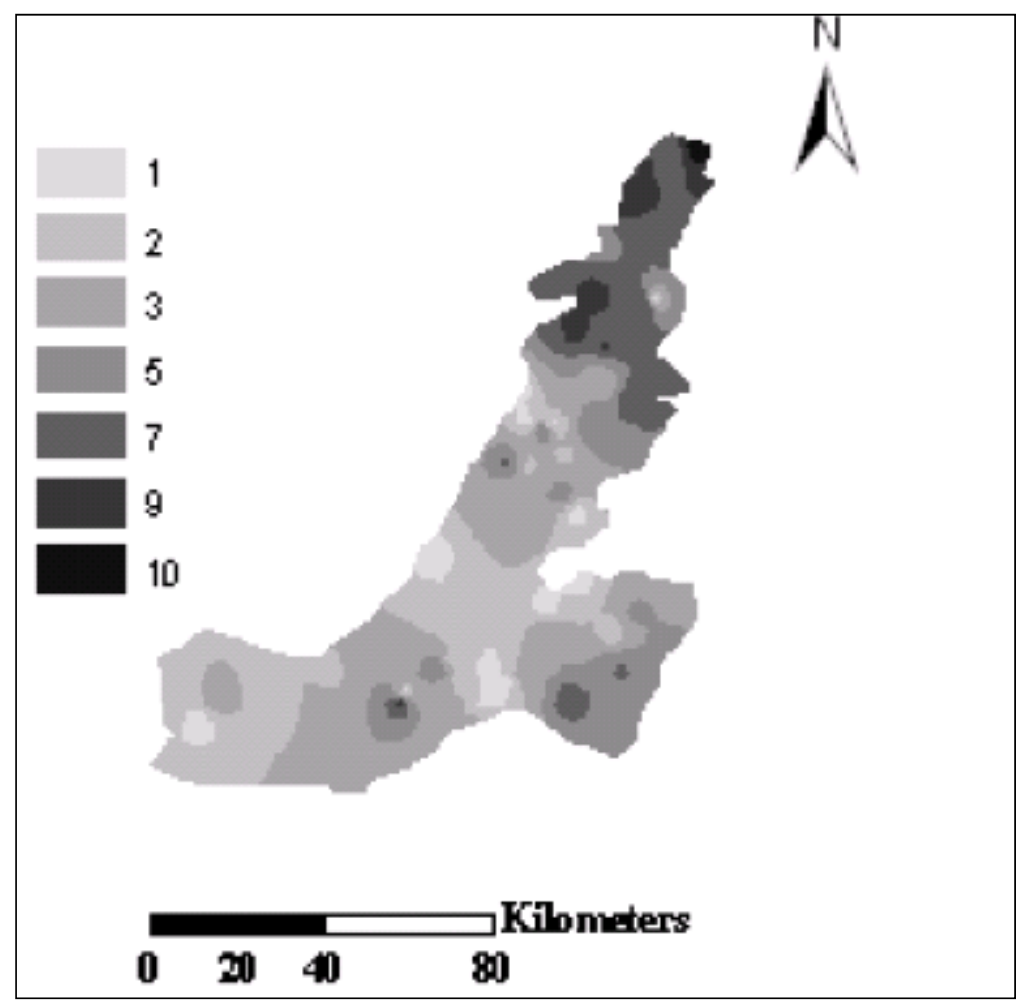

Figure 2. Depth to water table 


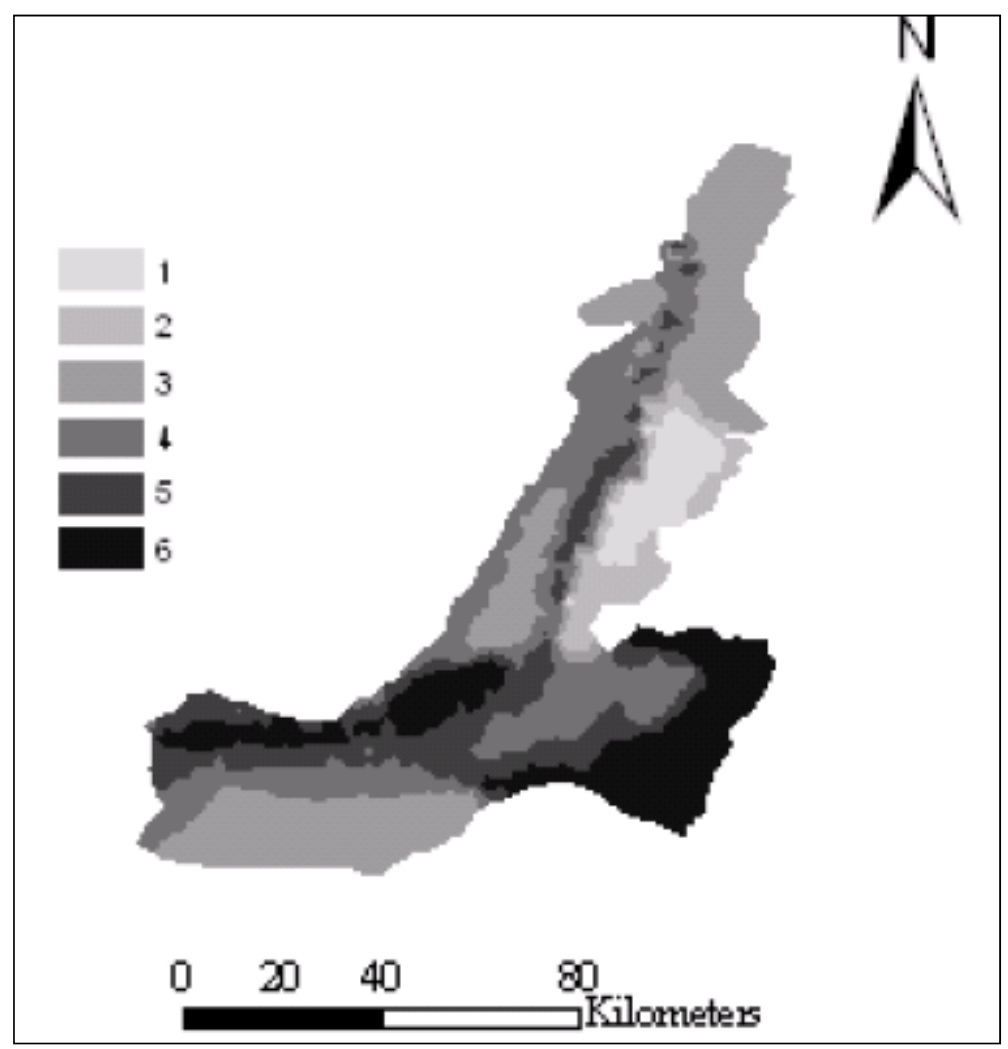

Figure 3. Net Recharge

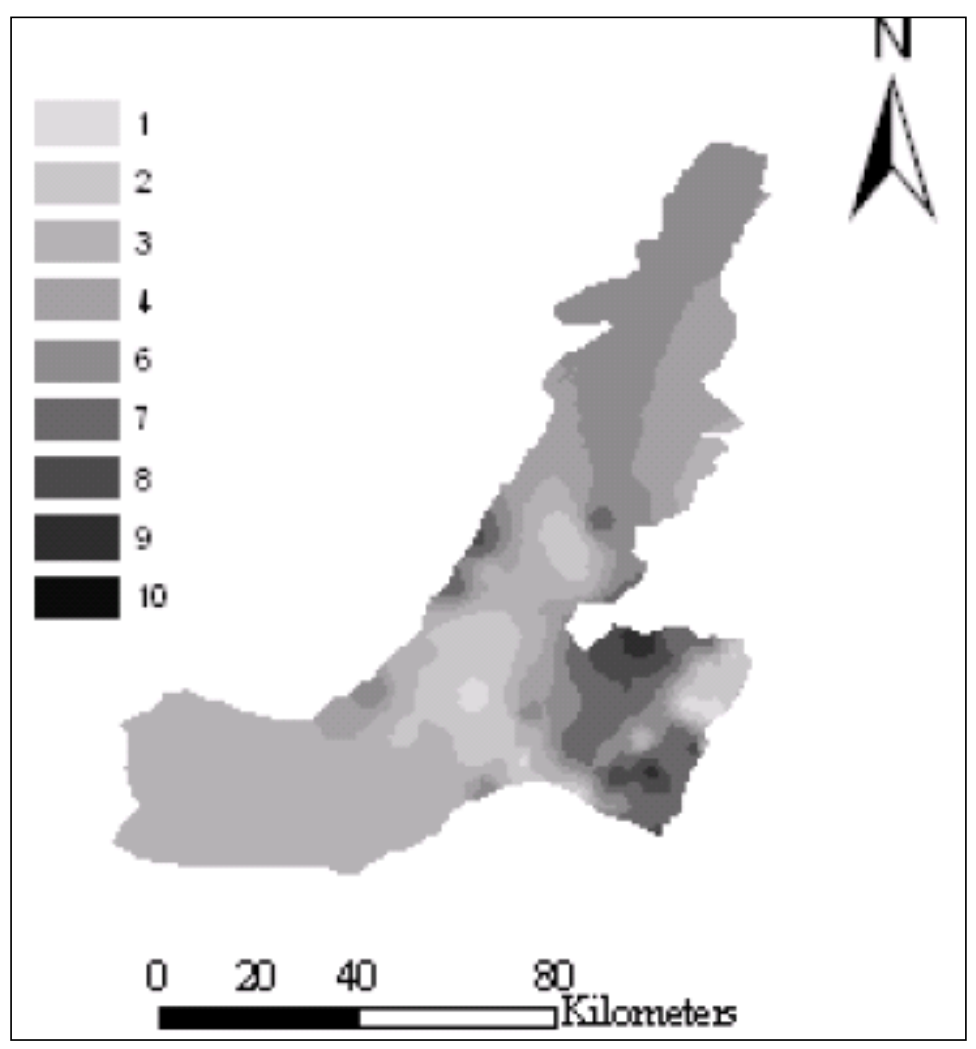

Figure 4. Aquifer Media 


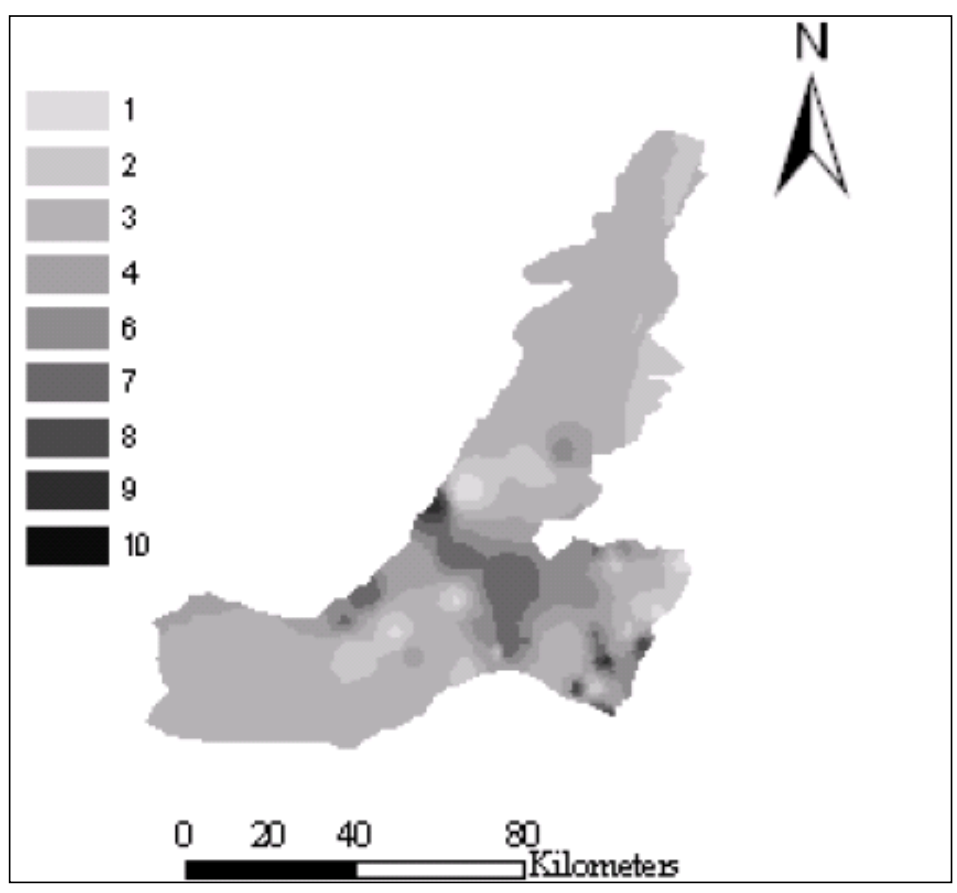

Figure 5. Soil Media

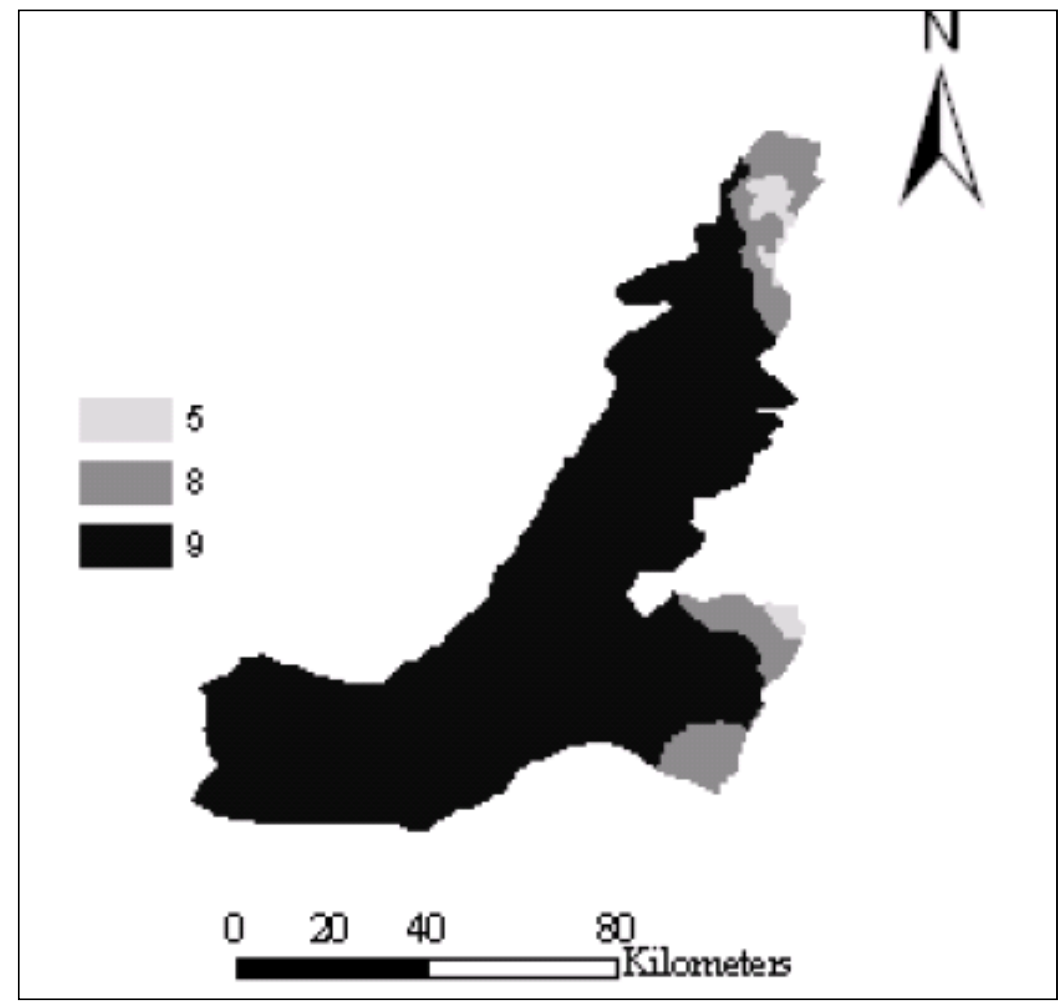

Figure 6. Topography 


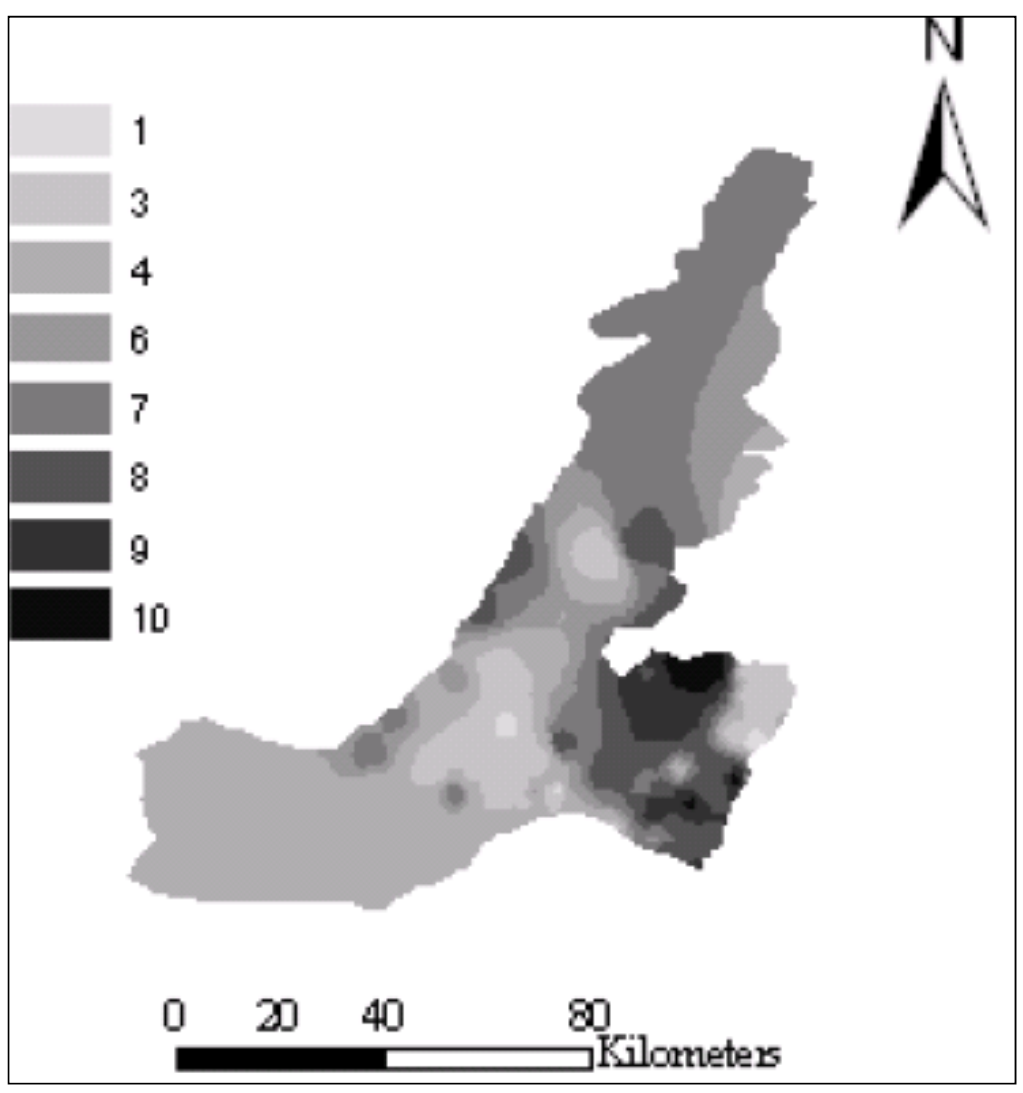

Figure 7. Impact of vadose zone

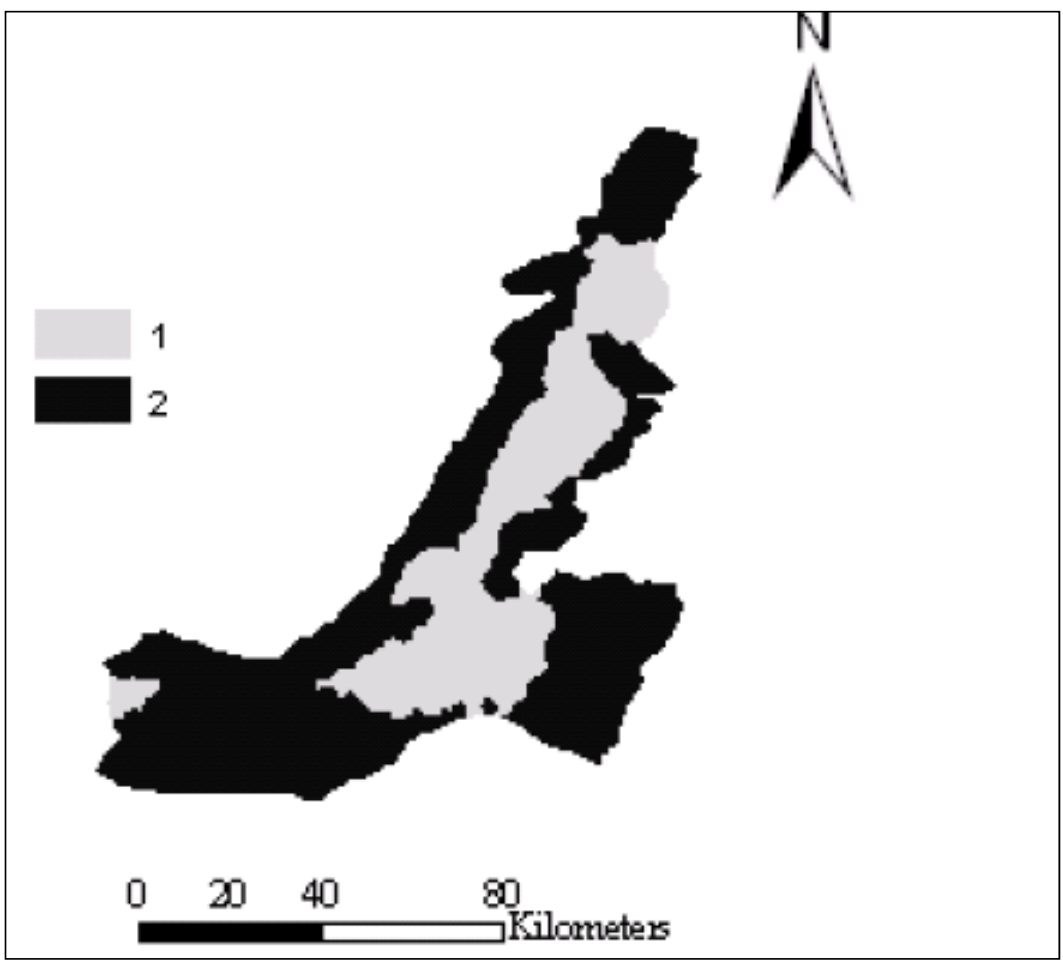

Figure 8 . Hydraulic conductivity 


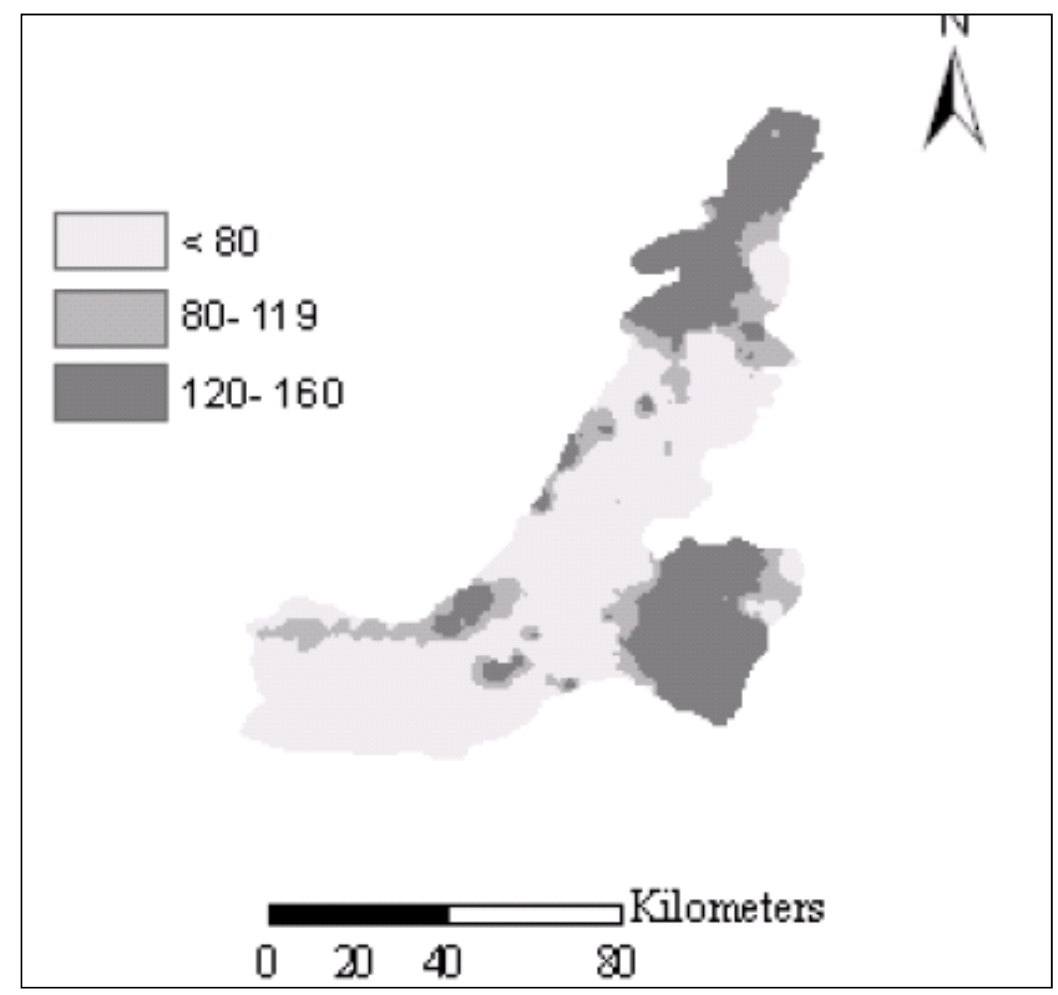

Figure 9. Aquifer vulnerability map

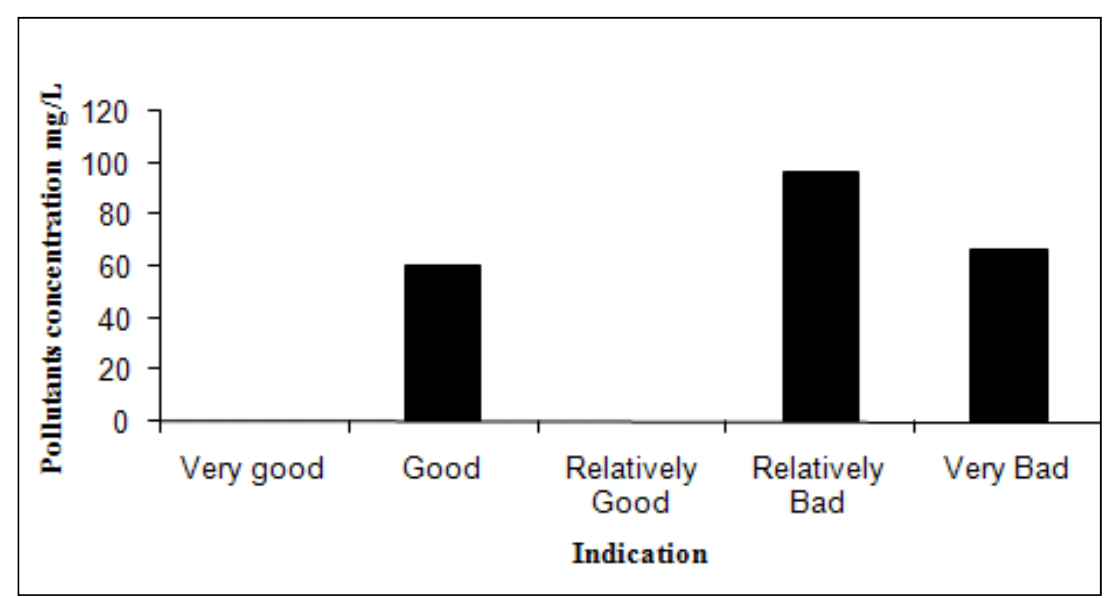

Figure 10. Water quality at Linfen Basin 